\title{
Effect of Monensin on Deoxyglucose Uptake in Cultured Astrocytes: Energy Metabolism is Coupled to Sodium Entry
}

\author{
P. Yarowsky, A. F. Boyne, R. Wierwille, and N. Brookes \\ Department of Pharmacology and Experimental Therapeutics, University of Maryland School of Medicine, \\ Baltimore, Maryland 21201
}

\begin{abstract}
This study was undertaken to measure the effect of maximal stimulation of sodium pump activity on the rate of energy metabolism in mouse cerebral astrocytes. The rate of uptake of ${ }^{3} \mathrm{H}$ 2-deoxyglucose ( $\left.{ }^{3} \mathrm{H}-2-\mathrm{DG}\right)$ was measured in astrocyte cultures sodium-loaded either by incubation in a $\mathrm{K}^{+}$-deficient solution or by use of the carboxylic sodium ionophore monensin. Sodiumloading by the first method caused ${ }^{3} \mathrm{H}-2-\mathrm{DG}$ uptake to increase by $80 \%$, but the effect was brief (about 5 min) compared with the period of uptake measurement $(20 \mathrm{~min})$. In contrast, the presence of monensin $(20 \mu \mathrm{M})$ caused a sustained 3.4-fold increase in the rate of ${ }^{3} \mathrm{H}-2-\mathrm{DG}$ uptake. The concentration-response relationship for monensin indicated a $K_{\mathrm{d}}$ of $1.5 \mu \mathrm{M}$ and a maximum uptake enhancement of approximately fourfold. The monensin-stimulated uptake of ${ }^{3} \mathbf{H}-2-D G$ was totally inhibited by incubation of the cultures in either $\mathrm{K}^{+}$-free or $\mathrm{Na}^{+}$-free solutions, or in the presence of ouahain ( $0.4 \mathrm{mM})$, indicating that the enhancement of uptake was the result of $\mathrm{Na}^{+}$influx and sodium pump activation. These results raise the possibility that astroglia contribute significantly to regional variations in glucose consumption associated with functional activity in the brain. Ultrastructural analysis showed that sodium-loading in $\mathrm{K}^{+}$-free solution caused swelling confined to the trans face of Golgi stacks. However, monensin (5 $\mu \mathrm{M})$ caused swelling of the entire Golgi stack, with progressively more severe swelling from cis to trans cisternae and formation of cytoplasmic vacuoles. Severe Golgi swelling was also observed on exposure of cultures to monensin in $\mathrm{Na}^{+}$-free solution, suggesting that monensin may penetrate intracellularly to the Golgi. The effects of monensin on ${ }^{3} \mathrm{H}-2-$ DG uptake and on Golgi morphology were rapidly and completely reversible, indicating that the $\mathrm{Na}^{+}$gradient in astrocytes is rapidly restored after perturbation.
\end{abstract}

Glucose is the major energy source of the CNS, and much of this energy is used to drive the active transport of $\mathrm{Na}^{+}$and $\mathrm{K}^{+}$. When neurons are electrically active, intracellular $\left[\mathrm{Na}^{+}\right]\left(\left[\mathrm{Na}^{+}\right]_{i}\right)$ rises, the activity of the sodium pump is stimulated, and there is an associated increase in the rate of use of glucose (Sokoloff, 1984). Mata et al. (1980) showed that the increase in glucose utilization on ficld stimulation of the rat postcrior pituitary, a tissue enriched in axon terminals, was eliminated by ouabain, which blocks the sodium pump. There is also evidence that

Received May 23, 1985; accepted Aug. 30, 1985.

This work was supported by U.S. Army Contract DAMD-17-81-C-1279 and NSF Grant BNS 81-19481. We thank Yvonne Logan and Robin Johnston for their capable technical assistance. We are grateful to Dr. George C. Stone for his critical reading of an earlier version of this manuscript. Portions of this study were presented at a meeting of the Society for Neuroscience (Yarowsky and Brookes, 1982) and at the IUPHAR 9th International Congress of Pharmacology (Brookes and Yarowsky, 1984).

Correspondence should be addressed to Dr. Neville Brookes, Department of Pharmacology and Experimental Therapeutics, University of Maryland School of Medicine, 660 W. Redwood Street, Baltimore, MD 21201.

Copyright (c) 1986 Society for Neuroscience $0270-6474 / 86 / 030859-08 \$ 02.00 / 0$ neurohumoral factors alter sodium pump activity in neurons (Phillis, 1977). Although CNS glial cells, like neurons, contain high levels of $\mathrm{Na}^{+}, \mathrm{K}^{+}$-ATPase activity (Atterwill et al., 1984, Kimelberg et al., 1978; Medzihradsky et al., 1972), little is known about the effect of neuronal activity or neurohumoral factors on glial sodium pump activity or how this affects glial energy metabolism.

We recently reported (Brookes and Yarowsky, 1985) that the resting rate of glucose utilization in primary cell cultures of mouse cerebral astrocytes, measured by the rate of uptake of ${ }^{3} \mathrm{H}$-2-deoxyglucose $\left({ }^{3} \mathrm{H}-2-\mathrm{DG}\right)$ tracer, was high $[75 \mu \mathrm{mol}$ glucose $/ 100 \mathrm{gm}$ wet weight $/ \mathrm{min}$-comparable to gray matter in vivo (Sokoloff et al., 1977)] and partially dependent upon sodium pump activity (approximately $50 \%$ in 2 - to 3 -week-old cultures). When the astrocytes were challenged by raised extracellular $\left[\mathrm{K}^{+}\right]$ $\left(\left[\mathrm{K}^{+}\right]_{\mathrm{o}}\right)$ in order to mimic the effects of neuronal activity, ${ }^{3} \mathrm{H}-$ $2-D G$ uptake increased by a maximum of $43 \%$, but most of this increase was not blocked by the sodium pump inhibitor ouabain. These findings raised the question whether the astrocytes possess any further reserve of $\mathrm{Na}^{+}, \mathrm{K}^{+}$-ATPase activity that can lead to increased rates of glucose use.

In the present study, we have attempted to detect such a reserve of functional $\mathrm{Na}^{+}, \mathrm{K}^{+}$-ATPase activity by measuring the effect on ${ }^{3} \mathrm{H}-2-\mathrm{DG}$ uptake of sodium-loading the astrocytes either by preincubation in a $\mathrm{K}^{+}$-deficient solution (Tang et al., 1980) or by use of the carboxylic $\mathrm{Na}^{+}$ionophore monensin (Pressman and Fahim, 1982). Tang et al. (1980) sodium-loaded the "all-glial" Necturus optic nerve by preincubation in $\mathrm{K}^{+}$deficient solution. Upon returning the nerve to normal- $\left[\mathrm{K}^{+}\right]$ solution they observed a hyperpolarization of the glial membrane, which was eliminated by strophanthidin; they concluded that glial cells possess an electrogenic sodium pump similar to that found in neurons. Lichtshtein et al. (1979) have shown that monensin produces a rapid influx of $\mathrm{Na}^{+}$and also ouabainsensitive hyperpolarization of the neuroblastoma-glioma hybrid, NG108-15. The present study demonstrates a large monensininduced enhancement of glucose use in mammalian astrocytes. This response is shown to depend entirely upon $\mathrm{Na}^{+}$influx and sodium pump activation. Although the effects of sodium-loading on glucose use and cell morphology were found to be rapidly reversible, evidence was obtained that monensin-induced swelling of the Golgi complex (Tartakoff, 1983) can occur independently of sodium-loading.

\section{Materials and Methods}

\section{Cell culture}

Primary cell cultures of astrocytes were prepared from the cerebral hemispheres of 1-d-old Dub:(ICR) outbred mice (Dominion Laboratories, Dublin, VA) as previously described (Brookes and Yarowsky, 1985). The cultures were grown to confluence in plastic dishes $(35 \mathrm{~mm}$ Nunc, GIBCO, Grand Island, NY), maintained in modified Eagle's 

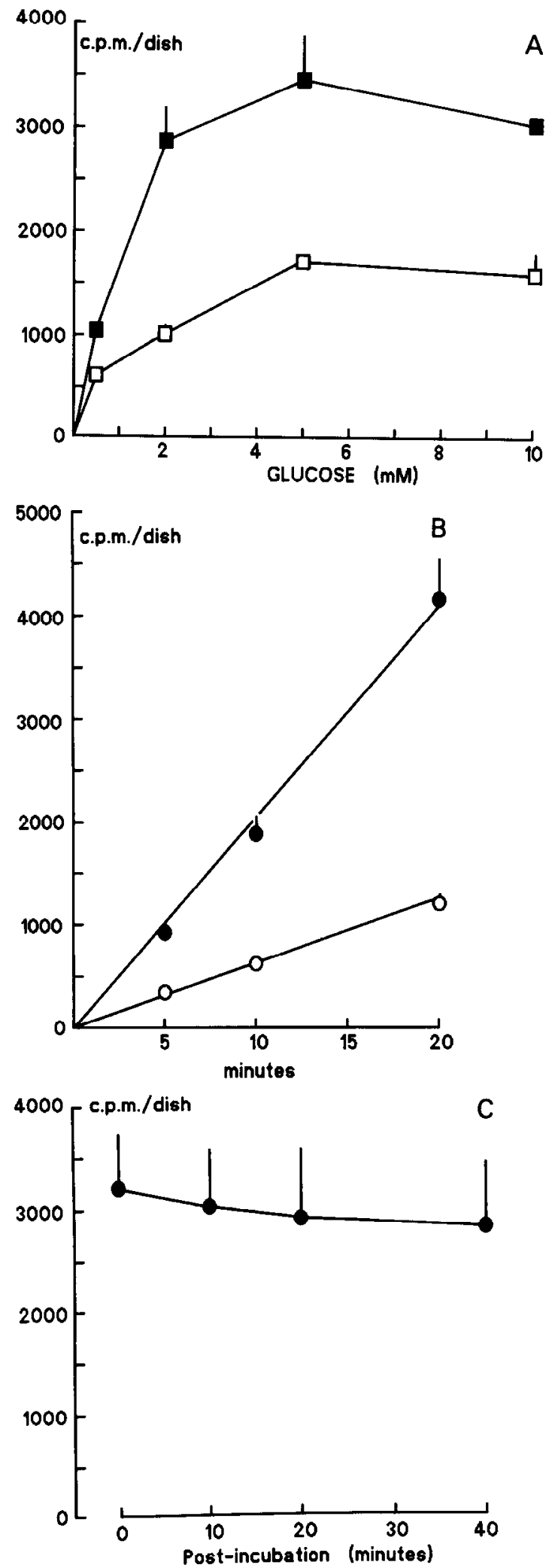

Figure 1. Effect of monensin on uptake and efflux of ${ }^{3} \mathrm{H}-2-\mathrm{DG}$ in astrocyte cultures. $A$, Dependence of uptake on glucose concentration. The glucose concentration of 5-5.6 mM in the uptake solution was sufficient to saturate the uptake process under control conditions (open squares) and when stimulated by $5 \mu \mathrm{M}$ monensin (filled squares). The ratio of ${ }^{3} \mathrm{H}-2-\mathrm{DG}$ to the molarity of glucose was maintained constant at different glucose concentrations. $B$, Linearity of ${ }^{3} \mathrm{H}-2-\mathrm{DG}$ uptake under control conditions (open circles) and when stimulated by $20 \mu \mathrm{M}$ monensin (filled circles). $C$, Rate of loss of ${ }^{3} \mathrm{H}$ from cultures previously medium (MEM, GIBCO) supplemented with $15 \%$ fetal calf serum (Flow Laboratories, McLean, VA), and incubated at $35.5-36.6^{\circ} \mathrm{C}$ in $10 \% \mathrm{CO}_{2} /$ $90 \%$ air. Since morphological differentiation of the astrocytes is suppressed under these conditions, some experiments were repeated using cultures in which "differentiation" was induced by removal of serum and addition of $0.1 \mathrm{mM}$ dibutyryl cAMP to the medium for approximately 1 week (Brookes and Yarowsky, 1985; Hertz et al., 1978; Shapiro, 1973). Cultures were used for experiments after a total of 2-3 weeks of incubation. Cell identity was based on criteria previously described (Brookes and Yarowsky, 1985).

\section{${ }^{3} \mathrm{H}$-2-Deoxyglucose uptake}

Uptake of ${ }^{3} \mathrm{H}-2-\mathrm{DG}$ was measured in a modified Earle's balanced salts solution (Earle's BSS) or, when it was necessary to change pH or remove $\mathrm{Na}^{+}$, a Tris-buffered salts solution (Tris BSS), as previously described (Brookes and Yarowsky, 1985). The composition of Earle's BSS (mM) was as follows: $\mathrm{NaCl} 110 ; \mathrm{KCl} 5.4 ; \mathrm{NaHCO}_{3} 50 ; \mathrm{CaCl}_{2} \quad 1.3 ; \mathrm{MgSO}_{4}$ $0.81 ; \mathrm{NaH}_{2} \mathrm{PO}_{4}$ 0.78; dextrose 5.6; HEPES 20; phenol red $0.001 \%$. The composition of Tris $\mathrm{BSS}$ (mM) was $\mathrm{NaCl} 150 ; \mathrm{KCl} 5 ; \mathrm{CaCl}_{2} ; \mathrm{MgCl}_{2} 0.8$; dextrose 5; Tris 20 . Both solutions were normally at $\mathrm{pH} 7.3$ and were adjusted to 345 mosm by addition of sucrose to match the osmolarity of the nutrient medium. Potassium concentration was reduced by isosmotic substitution of $\mathrm{NaCl}$ for $\mathrm{KCl}$, and choline chloride replaced $\mathrm{NaCl}$ in $\mathrm{Na}^{+}$-free Tris BSS. A tracer dose of ${ }^{3} \mathrm{H}-2-\mathrm{DG}$ [2-(1,2- $\left.{ }^{3} \mathrm{H}\right)$-deoxy-Dglucose, $40 \mathrm{Ci} / \mathrm{mmol}$, New England Nuclear Corp., Boston, MA] was added to $1 \mathrm{ml}$ BSS in each culture dish to yield a final 2-DG concentration of approximately $20 \mathrm{~nm}$ (BSS contained 5-5.6 mM glucose). The cultures were incubated at $34.5^{\circ} \mathrm{C}$ for $20 \mathrm{~min}$ in $10 \% \mathrm{CO}_{2} / 90 \%$ air (Earle's BSS) or air (Tris BSS). After termination of uptake with four washes of ice-cold BSS, the astrocytes were lysed with distilled water, and the ${ }^{3} \mathrm{H}$ content of the lysate was measured by liquid scintillation counting. Uptake of ${ }^{3} \mathrm{H}-2-D G$ is generally expressed as $\mathrm{cpm}$ of ${ }^{3} \mathrm{H} / \mathrm{dish} /$ $20 \mathrm{~min}$. The scatter of uptake values is indicated by the SD of the mean, except where SEM is used to indicate the scatter of mean uptake values in replicate experiments. Assuming a protein content of $75 \mu \mathrm{g}$ (mean value previously determined in sample 3 week cultures), an uptake of $1000 \mathrm{cpm} / \mathrm{dish} / 20 \mathrm{~min}$ corresponds to $0.66 \mathrm{pmol}{ }^{3} \mathrm{H}-2-\mathrm{DG} / \mathrm{mg}$ protein/ $20 \mathrm{~min}$ (Brookes and Yarowsky, 1985).

It was previously shown (Brookes and Yarowsky, 1985) that $5.6 \mathrm{~mm}$ glucose in Earle's BSS was sufficient to saturate the uptake mechanism and that the uptake rate was constant during the 20 min incubation. Figure $1, A$ and $B$, shows that these conditions were also satisfied during marked enhancement of uptake caused by monensin. However, uptake was decidedly nonlinear following the sodium-loading procedure in low $\left[\mathrm{K}^{+}\right]_{\mathrm{o}}$ described below (see Results).

In order for the rate of accumulation of label in these experiments to be considered a valid measure of glucose use, it was necessary to ascertain that, even when uptake was accelerated by monensin, the labeled species was substantially ${ }^{3}$ H-2-DG-6-phosphate (Sokoloff et al., 1977). An anion exchange column (Cunningham and Cremer, 1981) was used to estimate the proportion of ${ }^{3} \mathrm{H}-2-\mathrm{DG}$ present in the phosphorylated form in lysates of cultures following uptake enhanced by $20 \mu \mathrm{M}$ monensin. The lysate was placed on a column $(2 \times 1 \mathrm{~cm})$ of Dowex AG-1 $\times 8$ (formate form) resin. Nonphosphorylated ${ }^{3} \mathrm{H}-2-\mathrm{DG}$ was eluted with $5 \mathrm{ml}$ water and ${ }^{3} \mathrm{H}-2-D G-6-$ phosphate was eluted with $10 \mathrm{ml}$ of $0.5 \mathrm{~m}$ ammonium formate; the fractions were then counted. The proportion of ${ }^{3} \mathrm{H}$ 2-DG in the phosphorylated form was found to be $87.5 \pm 2.5 \%$ (SEM; $n=10$ ). The activity of glucose-6-phosphatase in our cultures was not known, although it is believed to be insignificant in glia (Anchors and Karnovsky, 1975). Thus, it was possible that accumulated 2-DG-6-phosphate might be broken down again to 2-DG during the 20 min uptake period. Figure $1 C$ shows that when cultures were loaded with ${ }^{3} \mathrm{H}-2-\mathrm{DG}$ in the presence of $20 \mu \mathrm{M}$ monensin and then returned to the incubator, the rate of loss of ${ }^{3} \mathrm{H}$ tracer was very low (less than $10 \%$ in $20 \mathrm{~min}$ ), indicating a negligible rate of breakdown of intracellular 2-DG-6-phosphate. Monensin, dibutyryl cAMP, ouabain, and choline chloride were obtained from Sigma Chemical Co. (St. Louis, MO).

incubated for $20 \mathrm{~min}$ with ${ }^{3} \mathrm{H}-2-\mathrm{DG}$ in the presence of $20 \mu \mathrm{M}$ monensin The uptake solution was removed and the cultures washed with Earle's BSS at time zero. Each value is the mean \pm SD for three to six cultures. 


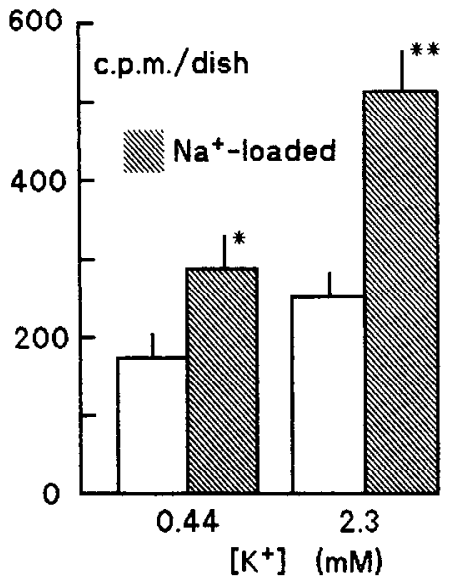

Figure 2. Effect of sodium-loading on ${ }^{3} \mathrm{H}-2-\mathrm{DG}$ uptake in astrocyte cultures: Cultures were sodium-loaded by preincubation in Earle's BSS containing $0.44 \mathrm{mM} \mathrm{K}^{+}$for $3 \mathrm{hr}$ immediately before uptake measurement. Control cultures were preincubated in normal Earle's BSS. Enhancement of ${ }^{3} \mathrm{H}-2$-DG uptake by sodium-loading is less marked $(+36 \%)$ in low- $\left[\mathrm{K}^{+}\right]$uptake solution than in normal-[K+ $\left.\mathrm{K}^{+}\right]$uptake solution $(+80 \%)$. Values are means $\pm \mathrm{SD}$ for five to six cultures. ${ }^{*}$, Different from control, $p<0.01$ (Student's $t$ test); ${ }^{* *} p<0.001$.

\section{Ultrastructure}

Cultures were prepared for electron microscopy either by quick-freezing (without cryoprotection) or by aldehyde fixation.

\section{Quick freezing}

Samples were delivered to a pure copper anvil at liquid nitrogen temperature using the "Gentleman Jim" system (Pelco Intl., Tustin, CA). A detailed description of the use of this instrument has been published (Phillips and Boyne, 1984). To optimize drainage of superficial solution from the cells, since the region free of disruption by ice crystals extends to a depth of only about $15 \mu \mathrm{m}$, the astrocytes were grown on microcarrier beads. Astrocytes were seeded in dishes containing collagencoated Thermanox plastic coverslips $(9 \times 30 \mathrm{~mm}$, Flow Laboratories); Cytodex 3 microcarrier beads (Pharmacia, Piscataway, NJ) were added before confluence. The astrocytes grew up over the beads, anchoring them to the coverslip. The beads formed readily drained prominences on the cut pieces of coverslip cultures, which were used as samples for quick-freezing. The samples were freeze-substituted for $3 \mathrm{~d}$ in tetrahydrofuran containing $1 \% \mathrm{OsO}_{4}$ (and usually $0.03 \%$ uranyl acetate) and then embedded in Epon-Araldite (Phillips and Boyne, 1984). The embedded blocks were trimmed down so that multiple Cytodex beads were present in the section face. Thin sections $(90 \mathrm{~nm})$ of these regions usually included well-frozen astrocytes at the top of the beads.

\section{Morphometry}

Quantification of cytoplasmic vacuolation was carried out on cultures aldehyde-fixed directly in the culture dish in order to accumulate the large numbers of cells required for statistical confidence. The fixation medium consisted of $2.5 \%$ glutaraldehyde in $0.15 \mathrm{M}$ cacodylate buffer, $\mathrm{pH} \mathrm{7.3,} \mathrm{to} \mathrm{which} 80 \mathrm{~mm} \mathrm{H}_{2} \mathrm{O}_{2}$ was added immediately before use. After $1 \mathrm{hr}$ of fixation at room temperature, the entire culture was rinsed in buffer, postfixed in $1 \% \mathrm{OsO}_{4}$ containing $1.5 \% \mathrm{~K}_{3} \mathrm{Fe}(\mathrm{CN})_{6}$, dehydrated through an ethanol series, and embedded.

Clusters of cells were then sawn out for ultramicrotomy. Thin sections were analyzed blind, and every cell in which the nucleus was visible was photographed at $\times 2800$. The micrographs were printed at $\times 9000$. The coherent double-lattice system of Weibel (1973) was used for the estimation of the percentage of cytoplasm volume, excluding the nucleus, that contained electron-lucent regions (swollen Golgi saccules and cytoplasmic vacuoles). Lattices were used with nine intersections $/$ in. ${ }^{2}$ for the coarse-point lattice (cytoplasmic volume) and 121 intersections/in. ${ }^{2}$ for the fine-point lattice (electron-lucent volume). After determination of the percentage of the cytoplasm occupied by swollen compartments, the micrographs and block numbers were decoded to plot the data presented in Table 1 and Figure 7.
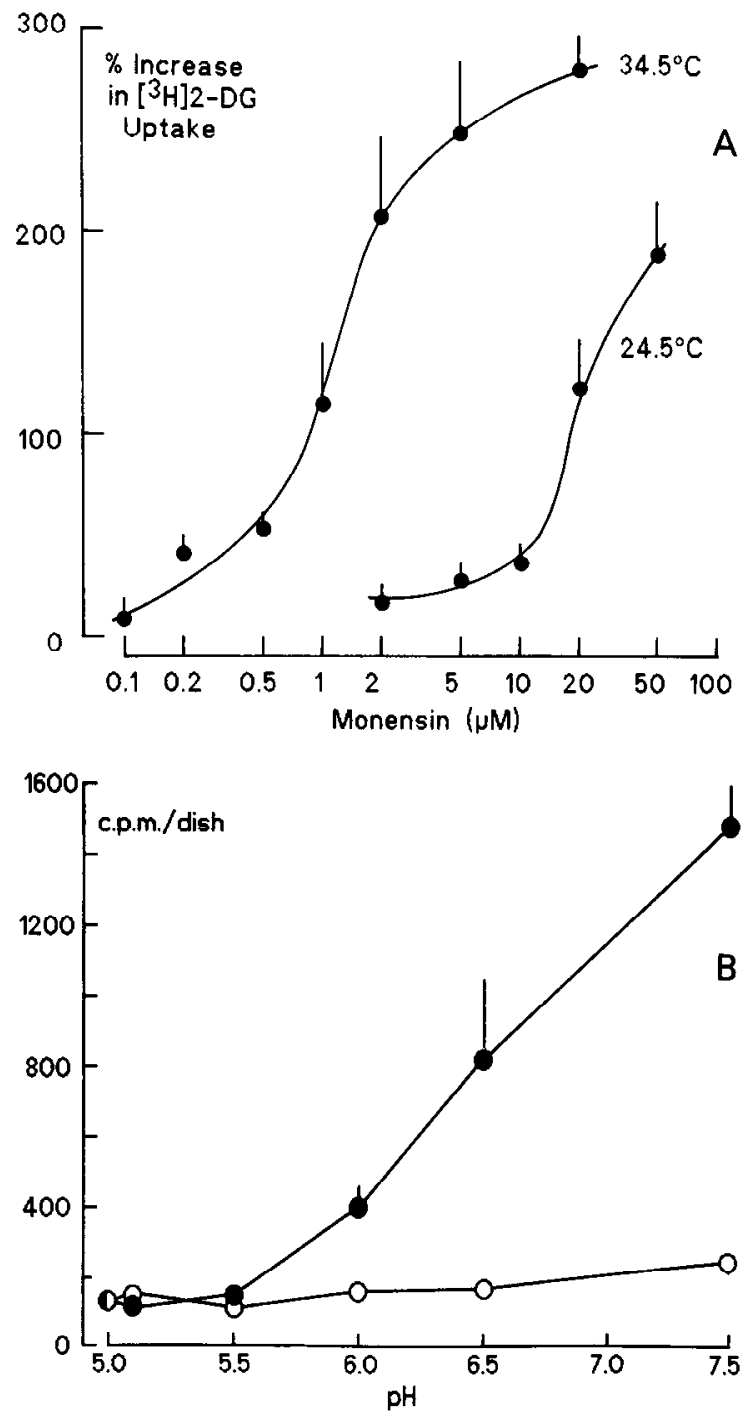

Figure 3. Dependence of monensin enhancement of ${ }^{3} \mathrm{H}-2-\mathrm{DG}$ uptake on concentration, temperature, and $\mathrm{pH} . A$, Log concentration-response curves for monensin at 34.5 and $24.5^{\circ} \mathrm{C}$. Values are means \pm SEM of three $\left(34.5^{\circ} \mathrm{C}\right)$ or six $\left(24.5^{\circ} \mathrm{C}\right)$ experiments. $B, \mathrm{pH}$ dependence of uptake in the presence (filled circles) and absence (open circles) of $5 \mu \mathrm{M} \mathrm{mo-}$ nensin. The $\mathrm{pH}$ of the Tris BSS uptake solution (bicarbonate-free) was adjusted by changing the ratio of Tris to Tris- $\mathrm{HCl}(20 \mathrm{~mm})$. Although outside of the effective buffering range of Tris, the $\mathrm{pH}$ of the solutions did not change during uptake measurement. Values are means \pm SD for three to six cultures.

\section{Results}

\section{Effect of sodium-loading}

Preincubation of astrocyte cultures in a $\mathrm{K}^{+}$-deficient solution was used to sodium-load the cells (Tang et al., 1980) so that the effect of sodium pump activation on ${ }^{3} \mathrm{H}-2-\mathrm{DG}$ uptake could be measured. We previously showed that sodium pump-dependent uptake of ${ }^{3} \mathrm{H}-2-D G$ in "resting" astrocytes is fully inhibited by lowering $\left[\mathrm{K}^{+}\right]_{\mathrm{o}}$ to $0.44 \mathrm{~mm}$ or less (Brookes and Yarowsky, 1985). Therefore, our sodium-loading procedure involved replacement of the nutrient medium with Earle's BSS containing $0.44 \mathrm{mM} \mathrm{K}^{+}$followed by returning the cultures to the incubator for $3 \mathrm{hr}$. This solution was changed to normal Earle's BSS, to permit pump reactivation, immediately before addition of tracer for uptake measurement. Control cultures were preincubated in normal Earle's BSS. The experiment in Figure 2 shows an $80 \%$ increase above the control rate of ${ }^{3} \mathrm{H}-2-\mathrm{DG}$ uptake produced 

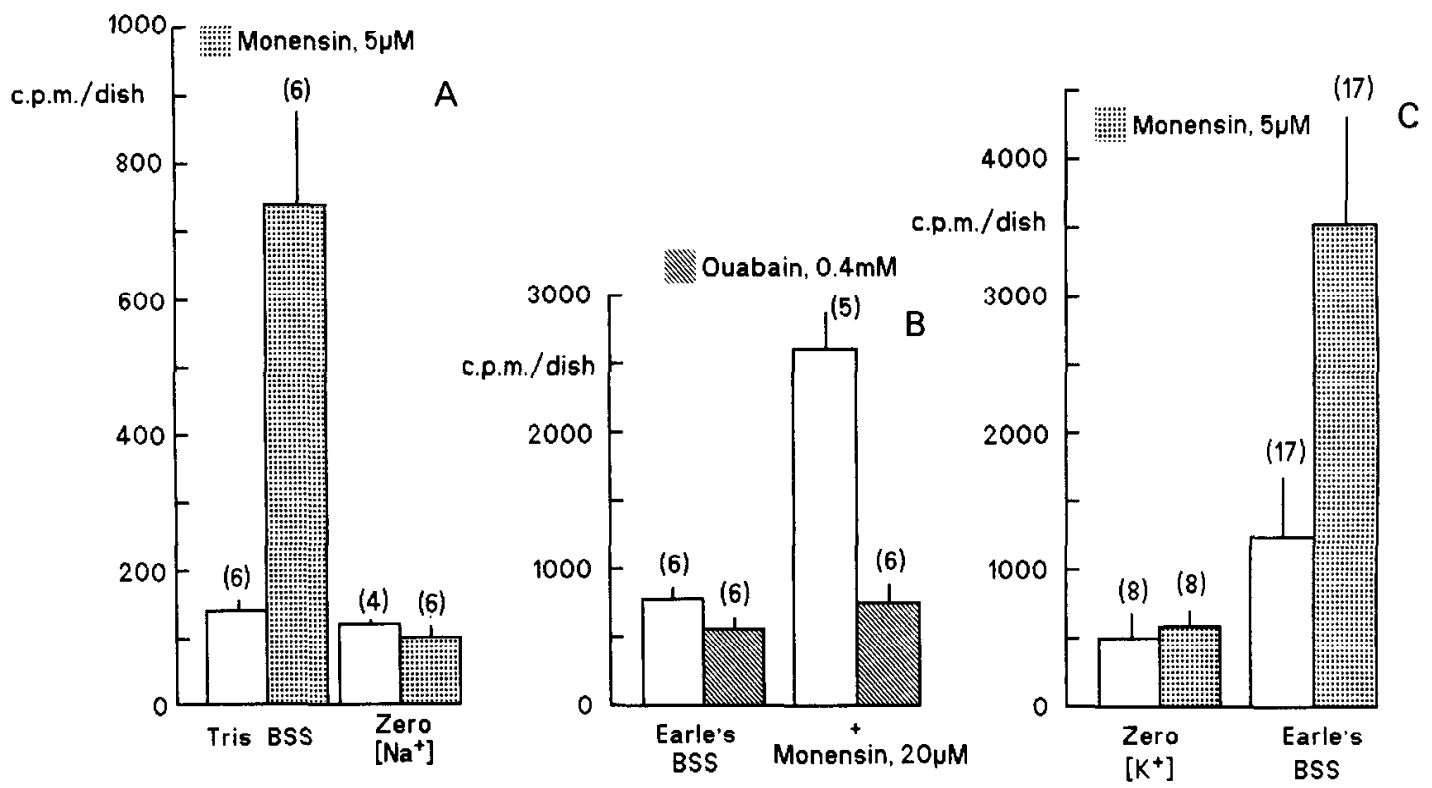

Figure 4. Effects of sodium removal and inhibition of the sodium pump on monensin enhancement of ${ }^{3} \mathrm{H}-2-\mathrm{DG}$ uptake. Monensin enhancement of uptake was abolished in zero-[ $\left[\mathrm{Na}^{+}\right]$solution $(A)$, in the presence of $0.4 \mathrm{~mm}$ ouabain $(B)$, or in zero-[K $\left.\mathrm{K}^{+}\right]$solution $(C)$. Values are means $\pm \mathrm{SD}$ for the number of cultures indicated in parentheses.

by this sodium-loading procedure. An indication that this response was at least partially attributable to sodium pump activation is given by the finding that uptake increased by only $36 \%$ when measured under conditions inhibitory to the sodium pump with $\left[\mathrm{K}^{+}\right]_{0}$ at $0.44 \mathrm{~mm}$ (Fig. 2).

In other sodium-loaded cultures, the mean rate of uptake during the first $5 \mathrm{~min}$ of the $20 \mathrm{~min}{ }^{3} \mathrm{H}-2-\mathrm{DG}$ incubation period with normal $\left[\mathrm{K}^{+}\right]_{0}\left(0.076 \mathrm{pmol}{ }^{3} \mathrm{H}-2-\mathrm{DG} / \mathrm{mg}\right.$ protein $\left./ \mathrm{min}\right)$ was about twice the mean rate during the final $10 \mathrm{~min}(0.036 \mathrm{pmol}$ ${ }^{3} \mathrm{H}-2-\mathrm{DG} / \mathrm{mg}$ protein $\left./ \mathrm{min}\right)$. The rate of uptake during the final $10 \mathrm{~min}$ was not different from the control rate $\left(0.037 \mathrm{pmol}{ }^{3} \mathrm{H}\right.$ $2-\mathrm{DG} / \mathrm{mg}$ protein $/ \mathrm{min}$ ). It appeared that recovery from sodiumloading was largely complete within $5 \mathrm{~min}$ of returning the cultures to normal $\left[\mathrm{K}^{+}\right]_{0}$. Thus, although this initial finding suggested a significant reserve of sodium pump activity, the rapid recovery rate from the effect of sodium-loading made it difficult to study quantitatively by the 2-DG method.

\section{Effect of monensin}

The $\mathrm{Na}^{+}$-selective carboxylic ionophore monensin offered an alternative approach to sodium-loading, by which a sodium influx could be sustained throughout the period of ${ }^{3} \mathrm{H}-2-\mathrm{DG}$ uptake. In 19 experiments, $20 \mu \mathrm{M}$ monensin produced a 3.4fold mean increase in ${ }^{3} \mathrm{H}-2-\mathrm{DG}$ uptake $( \pm 0.14 \mathrm{SEM})$, and this marked increase in rate of uptake remained constant during the $20 \mathrm{~min}$ incubation (Fig. 1B). The log concentration-response relationship for monensin is shown in Figure $3 A$. By use of an estimated maximum response of $300 \%$ at $34.5^{\circ} \mathrm{C}$, these same data yield a linear Hill plot with a slope of 1.2 (correlation coefficient of 0.985 ) and a $K_{\mathrm{d}}$ of $1.5 \mu \mathrm{M}$. As shown in Figure $3 \mathrm{~A}$, a $10^{\circ} \mathrm{C}$ reduction in temperature is associated with at least a 10 fold increase in apparent $K_{\mathrm{d}}$. This is consistent with the sensitivity of monensin to membrane lipid viscosity, and the marked slowing of monensin-mediated ion transport at reduced temperature (Tartakoff, 1983).

Monensin forms ionophoric complexes with cations readily only when in an ionized state, which is favored at physiological $\mathrm{pH}$ and above (Pressman and Fahim, 1982). If the effect on uptake is a consequence of the ionophoric property of monensin, it is anticipated that the effect would decline with reduction in $\mathrm{pH}$. Figure $3 B$ shows that the appropriate $\mathrm{pH}$ dependence was observed. Uptake in control cultures also declined significantly on lowering $\mathrm{pH}$ in this bicarbonate-free solution (Tris BSS) as previously reported (Brookes and Yarowsky, 1985), but the decline is made less obvious in Figure $3 B$ by the compressed scale of the ordinate.

The effect of monensin was also examined in astrocyte cultures showing morphologic differentiation induced by pretreatment with dibutyryl cAMP in serum-free medium (see Materials and Methods; Brookes and Yarowsky, 1985). The activity of $\mathrm{Na}^{+}, \mathrm{K}^{+}$-ATPase is reported to be elevated in such cultures (Kimelberg et al., 1978; Moonen and Franck, 1977; Schousboe et al., 1976). However, $5 \mu \mathrm{M}$ monensin produced an apparently smaller enhancement of ${ }^{3} \mathrm{H}-2-\mathrm{DG}$ uptake in differentiated cultures. The increase in differentiated cultures was $130 \pm 76 \%$ (SD, four experiments) compared with $246 \pm 60 \%$ in matched undifferentiated cultures. This apparent difference was of only marginal statistical significance $(0.05<p<0.1$, Student's $t$ test for paired data).

\section{Mechanism of monensin effect}

Substitution of choline chloride for $\mathrm{NaCl}$ in Tris BSS completely eliminated the effect of $5 \mu \mathrm{M}$ monensin on ${ }^{3} \mathrm{H}-2-\mathrm{DG}$ uptake (Fig. $4 A$ ), in accord with the notion that the response was mediated by entry of $\mathrm{Na}^{+}$into the astrocytes. Similarly, the response to monensin was reduced by $86 \%$ after substitution of $\mathrm{KCl}$ for $\mathrm{NaCl}$ in Earle's BSS (not shown). To determine whether $\mathrm{Na}{ }^{\prime}$ influx stimulates ${ }^{3} \mathrm{H}-2-\mathrm{DG}$ uptake through activation of the sodium pump, the response to monensin was examined under conditions in which the sodium pump is inhibited. The complete block of the monensin response observed in the presence of 0.4 mM ouabain (Fig. $4 B$ ) provides strong evidence for the involvement of the sodium pump. Further support for the role of the sodium pump is provided by the experiment in Figure $4 C$, showing complete block of the monensin response on removal of $\mathrm{K}^{+}$from Earle's BSS. It will be noted that reduction of $\left[\mathrm{K}^{+}\right]$ to $0.44 \mathrm{~mm}$ only partially blocked the enhancement of uptake by sodium-loading in Figure 2 . Similarly, a $\left[\mathrm{K}^{+}\right]_{\mathrm{o}}$ of only 0.2 $\mathrm{mM}$ was found to support a $94 \%$ increase in uptake on exposure of cultures to $5 \mu \mathrm{M}$ monensin (not shown). This contrasts with sodium pump-dependent ${ }^{3} \mathrm{H}-2-\mathrm{DG}$ uptake in resting astrocytes, 
Table 1. Morphometric analysis of Golgi swelling and vacuolation in astrocytes exposed for $20 \mathrm{~min}$ to zero- $\left[\mathrm{K}^{+}\right]$solution or $5 \mu \mathrm{M}$ monensin

\begin{tabular}{lll} 
& \multicolumn{2}{l}{$\begin{array}{l}\text { Percentage vacuolation of } \\
\text { non-nuclear cytoplasm }\end{array}$} \\
\cline { 2 - 3 } & $\begin{array}{l}\text { Normal } \\
\text { Tris BSS }\end{array}$ & $\begin{array}{c}\text { Zero-[K+] } \\
\text { Tris BSS }\end{array}$ \\
\hline Untreated & $2.4 \pm 0.7(9)$ & $6.7 \pm 1.0(23)$ \\
Monensin, $5 \mu \mathrm{M}$ & $5.6 \pm 0.7(10)$ & $10.0 \pm 0.9(25)$ \\
\hline
\end{tabular}

Morphometry was carried out on aldehyde-fixed astrocytes as described in Materials and Methods. Values are means \pm SEM for the number of cells indicated in parentheses. All differences are statistically significant $(p<0.01$; Student's $t$ test).

which is completely blocked on lowering $\left[\mathrm{K}^{+}\right]_{0}$ to $0.44 \mathrm{mM}$ (Brookes and Yarowsky, 1985).

\section{Reversibility of monensin effect}

Since the stimulation of ${ }^{3} \mathrm{H}-2-D G$ uptake was elicited in a high range of monensin concentration, and because monensin has been shown to cause morphological disruption (Tartakoff, 1983), we considered it necessary to demonstrate reversibility. Furthermore, if this effect was indeed a direct function of sodiumloading of the astrocytes, the brief effect of sodium-loading by preincubation in $\mathrm{K}^{+}$-deficient solution suggests that recovery from monensin should be rapid.

The 20 min uptake period was begun at varying intervals (recovery times) following a $20 \mathrm{~min}$ exposure of astrocyte cultures to $5 \mu \mathrm{M}$ monensin. Uptake was plotted against recovery time, as shown in Figure 5. Although it was expected that uptake rates would not be constant after short recovery times, only total ${ }^{3} \mathrm{H}$-2-DG uptake over $20 \mathrm{~min}$ was measured. Figure $5 A$ shows that recovery from the effect of monensin was $78 \%$ complete after the shortest recovery time studied, which was 5 min. However, the continuing downward trend of the recovery curve at recovery times of 20-60 min (Fig. 5A) could be interpreted as an indication of cell degeneration rather than recovery. A longerterm recovery experiment was therefore carried out, as shown in Figure $5 B$. This experiment demonstrated that uptake measured $24 \mathrm{hr}$ after a $20 \mathrm{~min}$ exposure to $5 \mu \mathrm{M}$ monensin was not different from control uptake.

\section{Ultrastructural studies}

Application of monensin to astrocytes correlated with progressive swelling of the Golgi complex after 5 to $20 \mathrm{~min}$ exposure periods, and the development of large vacuoles in the cytoplasm (Fig. 6, $A$ and $B$ ). Similar ultrastructural changes have been reported in a number of other cell types (Tartakoff, 1983). As can be scen in Figure $6 B$, the cis-face cisternum frequently retained a near-normal volume, but swelling became more pronounced in the cis-trans direction across the stack. Spherical vacuoles appeared to arise from the trans cisternum. The figure also illustrates the tendency for the Golgi cisternae to adhere even when swollen. On the other hand, spherical vacuoles appear to have a much weaker attachment to the stack and may be free to migrate into the cytoplasm. Both of these swollen compartments had a floccular inclusion.

The extent of Golgi swelling and vacuolation was quantitated (see Materials and Methods) in aldehyde-fixed cells exposed for $20 \mathrm{~min}$ to Tris BSS in the presence and absence of $5 \mu \mathrm{M} \mathrm{mo-}$ nensin, or to $\mathrm{K}^{+}$-free Tris BSS in the presence and absence of $5 \mu \mathrm{M}$ monensin. As shown in Table 1, the degree of swelling induced by monensin when the sodium pump was inactivated in $\mathrm{K}^{+}$-free solution was significantly greater than that produced by monensin alone. Table 1 shows that swelling of the Golgi and vacuole formation occurred also in $\mathrm{K}^{+}$-free solution without monensin, as has been reported by Tartakoff and Vassalli (1978) in other cell types. Micrographs of quick-frozen cells in this
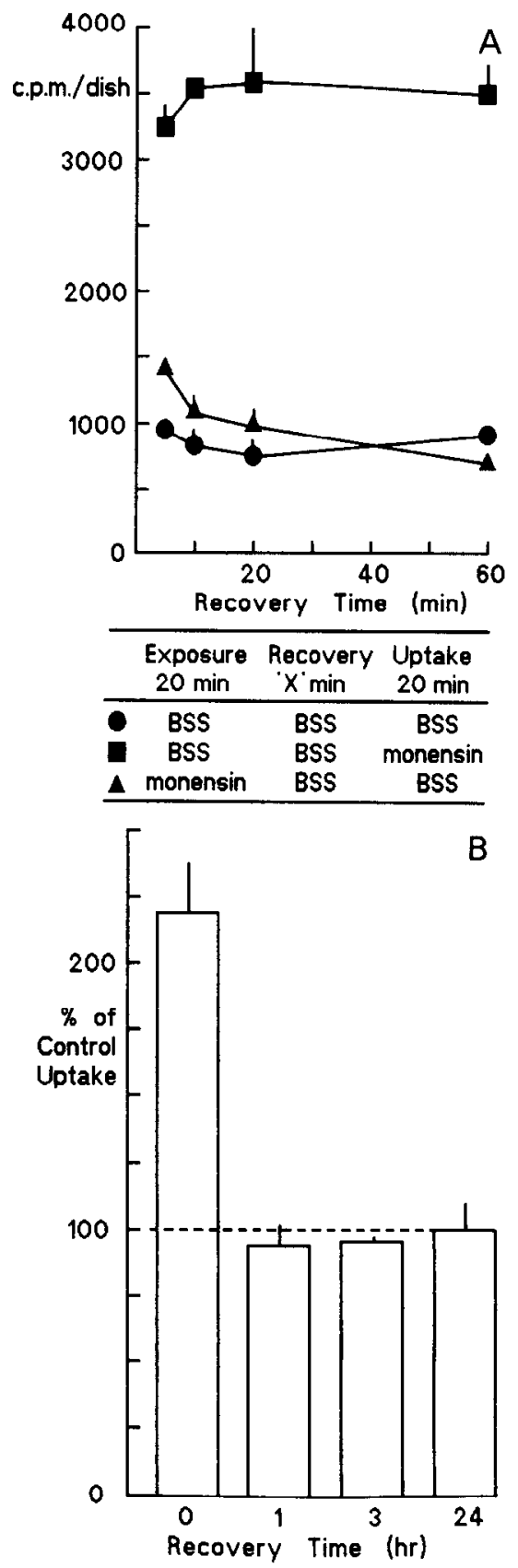

Figure 5. Rate of recovery of ${ }^{3} \mathrm{H}-2-\mathrm{DG}$ uptake after exposure to monensin. Short-term $(A)$ and long-term $(B)$ recoveries following a $20 \mathrm{~min}$ exposure to $5 \mu \mathrm{M}$ monensin are illustrated. $A$, Time course of recovery of uptake (triangles) is plotted along with controls unexposed to monensin (circles) and controls for uptake in the presence of monensin (squares). B. The zero recovery time column shows uptake in the presence of monensin. Values are mean \pm SEM for two experiments.

condition showed a relatively selective swelling of the trans Golgi cisternum, which became broken up into vacuoles. Although these vacuoles were smaller than those illustrated in Figure $6 \mathrm{~B}$, they also appeared to have lost adherence to the Golgi stack and to have drifted off into the cytoplasm.

In another experiment, astrocytes were exposed to $5 \mu \mathrm{M} \mathrm{mo-}$ nensin in $\mathrm{Na}^{+}$-free Tris BSS for 20 min to see whether the morphological effects of monensin could be eliminated by preventing an influx of $\mathrm{Na}^{+}$. Sodium-free solution alone produced no effect on Golgi morphology (Fig. 6C). However, in $\mathrm{Na}^{+}$-free solution, $5 \mu \mathrm{M}$ monensin still caused marked Golgi swelling and vacuole formation (Fig. $6 D$ ). The reversibility of ultrastructural 

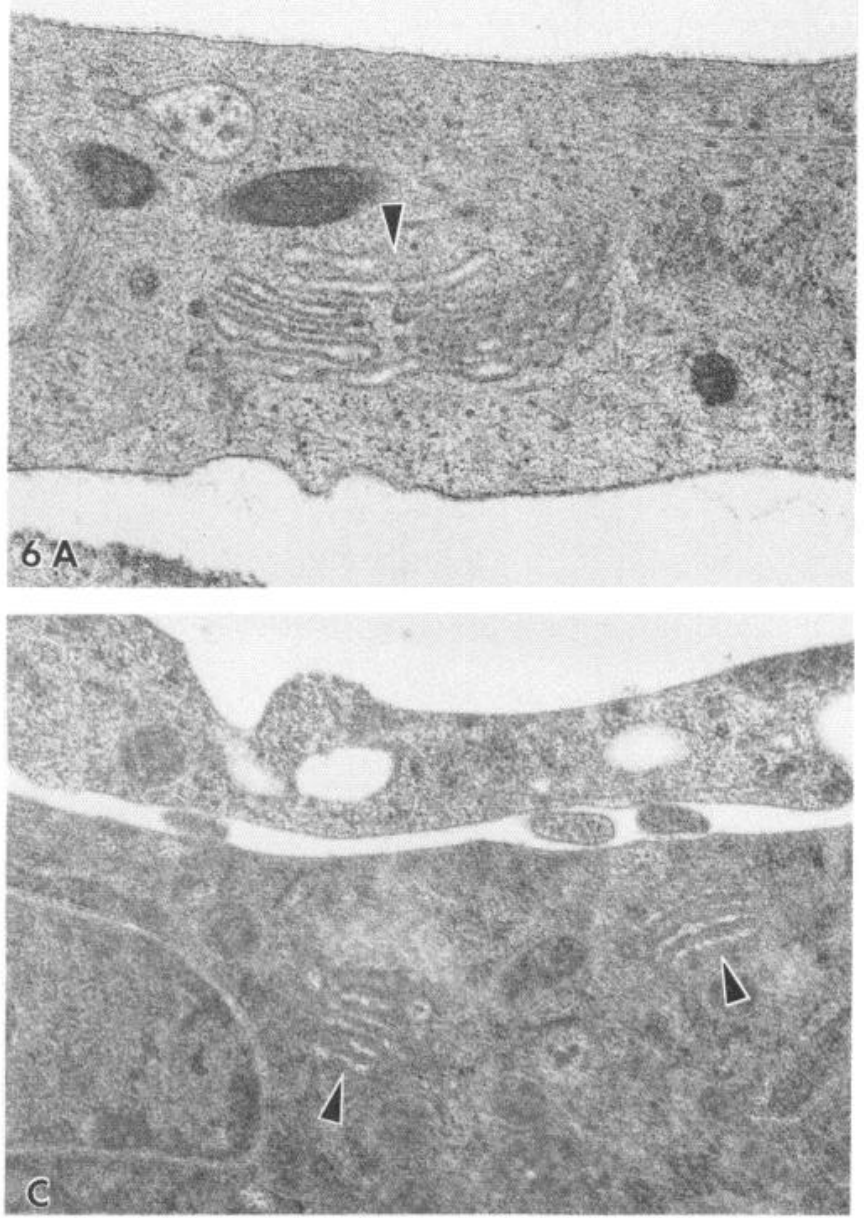
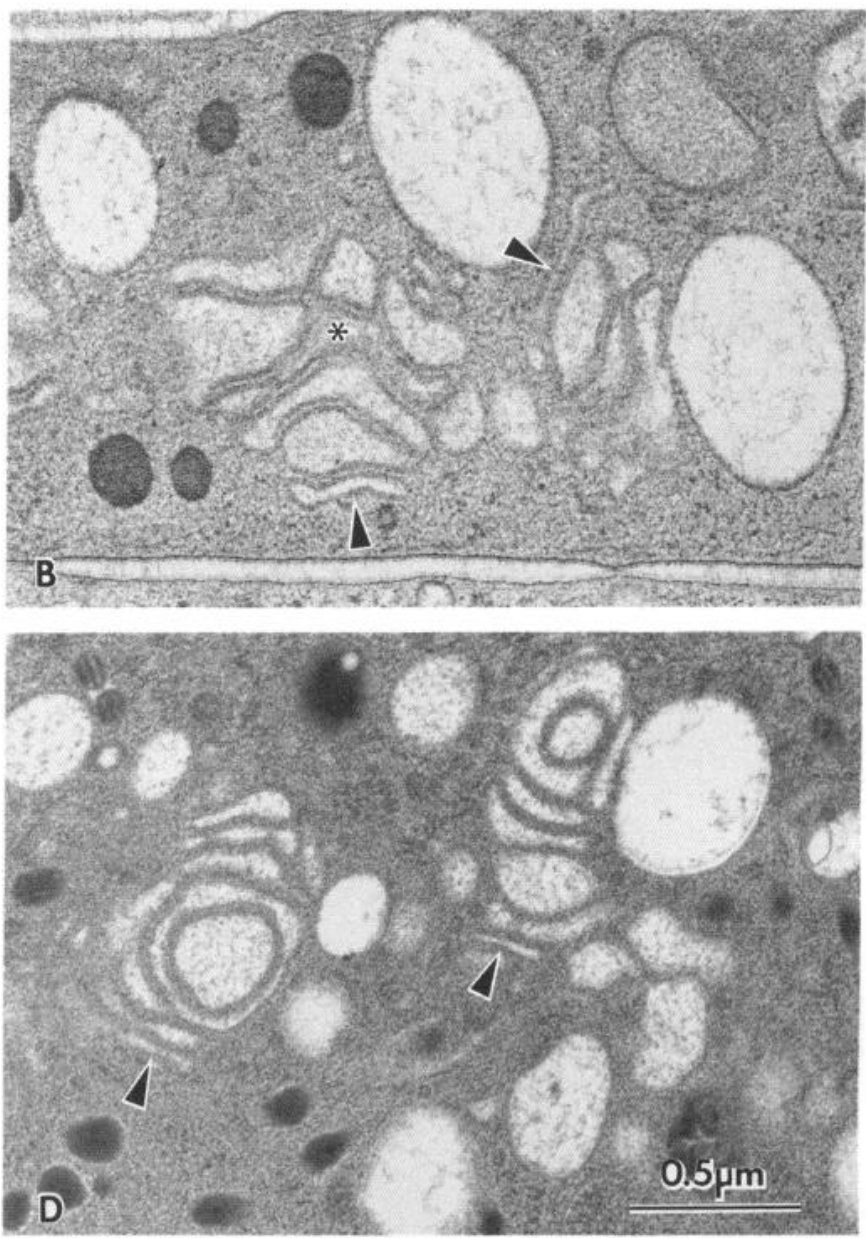

Figure 6. Electron micrographs of quick-frozen fixed astrocytes showing the effect on the Golgi apparatus of a 20 min exposure to monensin in normal and zero- $\left[\mathrm{Na}^{+}\right]$solutions. Arrows, The cis face of Golgi stacks in the dense cytoplasm typical of freeze-substituted preparations (see Materials and Methods). Magnification, $\times 35,500$. Unperturbed Golgi stacks are apparent in control cells exposed for 20 min to normal Tris BSS $(A)$ or zero$\left[\mathrm{Na}^{+}\right]$Tris BSS $(C)$. Massive Golgi swelling and vacuole generation are seen after 20 min exposure to $20 \mu \mathrm{M}$ monensin in normal Tris BSS $(B)$ or to $5 \mu \mathrm{M}$ monensin in zero- $\left[\mathrm{Na}^{+}\right]$Tris BSS $(D)$. The tendency of the swollen cisternae to adhere is evident $\left({ }^{*}\right)$, in contrast to the rounded vacuoles which appear to be detaching from the stack $(B, D)$.

changes was studied after exposure of astrocytes to the conditions eliciting most marked vacuolation $-5 \mu \mathrm{M}$ monensin in $\mathrm{K}^{+}$free Tris BSS for $20 \mathrm{~min}$. Figure 7 shows that the percentage of vacuolation recovered to control levels within $20 \mathrm{~min}$ of returning the cultures to normal Tris BSS.

\section{Discussion}

Our findings provide strong evidence that mammalian astrocytes in their "resting" state possess a large reserve of $\mathrm{Na}^{+}, \mathrm{K}^{+}$ATPase activity, which, when activated by entry of $\mathrm{Na}^{+}$, can trigger a three- to fourfold increase in rate of glucose consumption. Since the estimated resting rate for mouse astrocyte cultures $(75 \mu \mathrm{mol}$ glucose $/ 100 \mathrm{gm}$ wet weight $/ \mathrm{min}$; Brookes and Yarowsky, 1985) is comparable to estimates for rat gray matter in vivo (Sokoloff et al., 1977), the possibility exists that regional changes in CNS glucose consumption associated with functional activity may reflect changes in the energy metabolism of astroglia, as well as neurons.

Recent evidence that rat brain astrocytes possess at least two distinct populations of $\mathrm{Na}^{+}$channels give added credence to this possibility. Bevan et al. (1985) reported the presence of voltage-dependent $\mathrm{Na}^{+}$channels in rat astrocytes, detected by the patch clamp technique and by labeled saxitoxin binding. Bowman et al. (1984) detected such channels using conventional microelectrode techniques only after exposure of astrocytes to veratridine. A second population of $\mathrm{Na}^{+}$channels was reported by Bowman and Kimelberg (1984), who showed that excitatory amino acids depolarize the astrocyte membrane by activating a $\mathrm{Na}^{+}$conductance that was unaffected by tetrodotoxin. In addition, we have recently reported that veratridine increases ${ }^{3} \mathrm{H}$ $2-\mathrm{DG}$ uptake in astrocyte cultures by $74 \%$ (Yarowsky and Brookes, 1984). However, $\mathrm{Na}^{+}$-dependent regenerative potentials have not been observed under normal circumstances in astroglia either in vivo (Somjen, 1975) or in vitro (Kimelberg et al., 1979; Walz and Hertz, 1983). Furthermore, large elevations in $\left[\mathrm{K}^{+}\right]_{0}$ had little effect on $\mathrm{Na}^{+}$influx measured in mouse astrocyte cultures (Walz and Hertz, 1984). Thus, at the moment, it seems more likely that any influence of neuronal activity on $\mathrm{Na}^{+}$influx in astrocytes will be neurohumorally mediated.

In addition to the above-mentioned evidence of a $\mathrm{Na}^{+}$current activated by excitatory amino acids, other evidence of astrocyte chemosensitivity has accumulated. Astrocytes have been reported to possess both alpha and beta adrenoceptors (Ebersolt et al., 1981; Harden and McCarthy, 1982). Whereas Kimelberg et al. (1983) found that norepinephrine depolarized rat astrocytes through activation of adrenergic alpha receptors, one of us has observed that the beta receptor agonist, isoproterenol, increased ${ }^{3} \mathrm{H}-2-\mathrm{DG}$ uptake in mouse astrocytes by $38 \%$ (Brookes, 1984). Marked effects of histamine $\mathrm{H}_{1}$ - and $\mathrm{H}_{2}$-agonists on the astrocyte membrane potential were recently reported by Hösli 


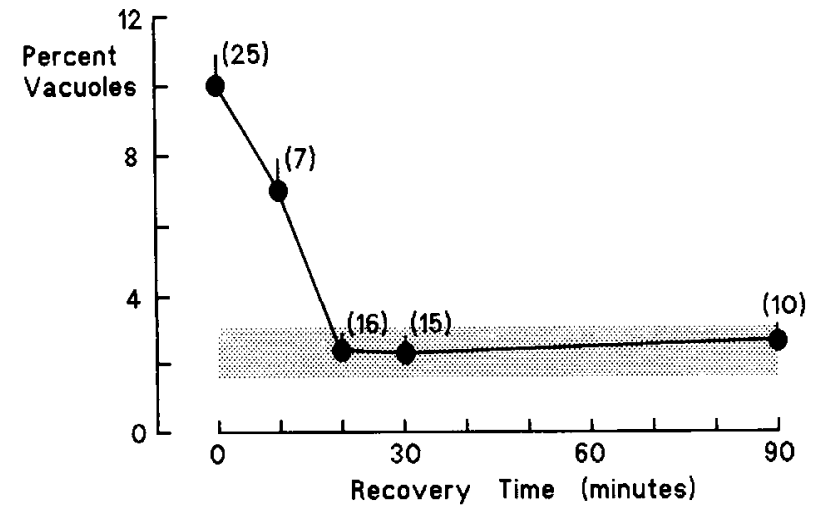

Figure 7. Morphometric analysis of recovery from Golgi swelling and cytoplasmic vacuolation in astrocytes, following a $20 \mathrm{~min}$ exposure to $5 \mu \mathrm{M}$ monensin in zero- $\left[\mathrm{K}^{+}\right]$Tris BSS. The percentage vacuolation was determined as described in Materials and Methods. The zero time point corresponds to the value in Table 1 for vacuolation at the end of the monensin exposure. The remaining points show the time course of recovery on restoring the cultures to normal medium. The shaded area indicates the range of vacuolation (mean \pm SEM, $n=9$ ) in control astrocyte cultures.

et al. (1984). It is not yet known which ionic conductances, if any, mediate these responses, or whether modulatory effects on sodium pump activity are involved.

The advantage of monensin as a means of sodium-loading the astrocytes in this study was that it could be present to exert a constant effect during uptake measurement. The effect of prior sodium-loading using low $\left[\mathrm{K}^{+}\right]_{0}$ to inhibit the sodium pump declined rapidly within the first few minutes after restoring the astrocytes to normal $\left[\mathrm{K}^{+}\right]_{0}$ for uptake measurement. The evidence that monensin-induced enhancement of ${ }^{3} \mathrm{H}-2-\mathrm{DG}$ uplake did indeed result from $\mathrm{Na}^{+}$entry and sodium pump activation is that it was abolished either by removal of extracellular $\mathrm{Na}^{+}$or by blockade of the sodium pump by means of ouabain or removal of extracellular $\mathrm{K}^{+}$. Evidence that monensin activates $\mathrm{Na}^{+}, \mathrm{K}^{+}$ATPase by raising $\left[\mathrm{Na}^{\prime}\right]_{i}$ has also been reported for neuroblastoma-glioma hybrid cells (Lichtshtein et al., 1979) and 3 T3 mouse fibroblasts (Smith and Rozengurt, 1978). It appears unlikely that uptake was modified by a rise in intracellular $\mathrm{pH}$ caused by $\mathrm{Na}^{+} /$ $\mathrm{H}^{+}$exchange, for intracellular $\mathrm{pH}$ in neuroblastoma-glioma hybrid cells returned spontaneously to control values within 5-7 min in the continuing presence of monensin (Lichtshtein et al., 1979).

It should be noted, though, that in other cell types there have been observed effects of monensin on glucose transport not mediated by sodium pump activation. For example, Nordenberg et al. (1984) found that monensin-induced enhancement of ${ }^{3} \mathrm{H}$-2-DG uptake in mouse thymocytes was unaffected by 2 mM ouabain. The uptake of $3-O$-methylglucose, which is transported but not phosphorylated (Lund-Andersen et al., 1976), was similarly enhanced. Bihler and Sawh (1984) found that conditions favoring an increase in free $\mathrm{Ca}^{2+}$ in the cytoplasm, including inhibition of the sodium pump or addition of monensin, enhanced influx of 3-O-methylglucose in rat cardiac myocytes. It is not clear to what extent differences in cell type or differences in experimental conditions determined the response to monensin in these studies. In the present study, glucose concentration was sufficiently high to saturate the transport carrier in order that phosphorylation of ${ }^{3} \mathrm{H}-2-\mathrm{DG}$ should be rate-limiting. These conditions do not favor detection of any effect of monensin on the carrier. In the above studies, the choice of cell type, substrate, and substrate concentration may have favored detection of effects on the carrier rather than on phosphorylation rate.

The apparent, though statistically equivocal, reduction in ef- fectiveness of monensin in morphologically differentiated astrocytes does not necessarily conflict with studies showing that morphologic differentiation elevates $\mathrm{Na}^{+}, \mathrm{K}^{+}$-ATPase activity (Kimelberg et al., 1978; Moonen and Franck, 1977; Schousboe et al., 1976). Other steps in the chain of events linking sodium entry to increased energy metabolism could be affected by the dibutyryl cAMP treatment that stimulates differentiation. Whether or not reduced, the effect of monensin on uptake was still marked in morphologically differentiated astrocytes, demonstrating that this response is not confined to immature or undifferentiated cells.

Our ultrastructural observations show that either sodiumloading of the astrocytes in the absence of monensin or addition of monensin in the absence of extracellular sodium was able to cause swelling of the Golgi apparatus cisternae. In either condition, a preferential sensitivity of the more mature trans cisternae was seen, as previously noted by Morré et al. (1983) in wild carrot cells. The ability of monensin to swell Golgi cisternae in the absence of extracellular sodium supports the view of Boss et al. (1984) that monensin acts by inserting in the cisternal membranes of intact cells as demonstrated for isolated Golgi membranes (Barr et al., 1984). Recent evidence that the Golgi membrane contains an inwardly directed proton pump in parallel with a chloride conductance (Barr et al., 1984; Glickman et al., 1983) suggests that monensin causes entry of water into cisternae by mediating the exchange of osmotically inactive intracisternal protons for osmotically active extracisternal $\mathrm{Na}^{+}$ (Boss et al., 1984). Since the effect of monensin on ${ }^{3} \mathrm{H}-2-\mathrm{DG}$ uptake was completely blocked in $\mathrm{Na}^{ }$-free solution, while the effect on the Golgi was still evident, it appears that the activity of the energy-driven Golgi proton pump and the processes leading to Golgi swelling do not contribute to the measured enhancement of energy metabolism.

The rapid recovery from the effect of monensin on ${ }^{3} \mathrm{H}-2-\mathrm{DG}$ uptake was consistent with the observation of only short-lasting enhancement of uptake after sodium-loading in low- $\left[\mathrm{K}^{+}\right]$solution. It appears likely that this rapid recovery occurred despite large increases in $[\mathrm{Na}]_{i}$. Lichtshtein et al. (1979) found that $\left[\mathrm{Na}^{+}\right]_{i}$ rose to equal the extracellular concentration after $20-30$ min of exposure of NG108-15 hybrid cells to $20 \mu \mathrm{M}$ monensin. Similarly, Feinstein et al. (1977) reported that $\left[\mathrm{Na}^{+}\right]_{i}$ reached the extracellular level in blood platelets after $5 \mathrm{~min}$ in $27 \mu \mathrm{M}$ monensin. Thus, it appears that the astrocytes are able to restore the $\mathrm{Na}^{+}$gradicnt very rapidly following even large perturbations. Investigations by Tang et al. (1980) demonstrated that strophanthidin-sensitive hyperpolarizations of neuroglia in $\mathrm{Nec}$ turus optic nerve lasted for less than $1 \mathrm{~min}$ following restoration of the normal bathing solution after sodium-loading. However, in that experiment electrogenicity of the sodium pump might not necessarily have paralleled changes in energy metabolism.

Recovery from monensin-induced Golgi swelling was almost as rapid as recovery of energy metabolism, being complete in only $20 \mathrm{~min}$. The mechanisms facilitating rapid morphologic recovery are not known. We have raised the possibility that the vacuolar contents discharge to the cell exterior (Boyne et al., 1984). This rapid morphologic recovery contrasts with reports of much slower recovery from monensin-induced inhibition of intracellular transport processes (Tartakoff, 1983).

In summary, we have demonstrated a striking effect of $\mathrm{Na}^{+}$ entry on astrocyte energy metabolism, mediated by sodium pump activation. We have also shown that recovery from the functional and morphologic effects of sodium-loading of astrocytes is remarkably rapid. Accumulating evidence of astroglial chemosensitivity points to the possibility of neurohumoral modulation of astroglial energy metabolism (Brookes, 1984). One of us has obtained autoradiographic evidence of preferential glial accumulation of labeled 2-DG in electrically stimulated sympathetic ganglia (Yarowsky et al., 1985). 


\section{References}

Anchors, J. M., and M. L. Karnovsky (1975) Purification of cerebral glucose-6-phosphatase. An enzyme involved in sleep. J. Biol. Chem. 250: 6408-6416.

Atterwill, C. K., V. J. Cunningham, and R. Balazs (1984) Characterization of $\mathrm{Na}^{+}, \mathrm{K}^{+}$-ATPase in cultured and separated neuronal and glial cells from rat cerebellum. J. Neurochem. 43: 8-18.

Barr, K. K., K. Safranski, I. L. Sun, F. L. Crane, and D. J. Morré (1984) An electrogenic proton pump associated with the Golgi apparatus of mouse liver driven by NADH and ATP. J. Biol. Chem. 259: 1406414067.

Bevan, S., S. Y. Chiu, P. T. A. Gray, and J. M. Ritchie (1985) Sodium channels in rat cultured astrocytes. J. Physiol. (Lond.) $361: 18 \mathrm{P}$

Bihler, I., and P. C. Sawh (1984) Calcium-dependent regulation of hexose transport in isolated cardiac myocytes. Abstr. IUPHAR Int. Congr. Pharmacol. 9: 593.

Boss, W. F., D. J. Morré, and H. H. Mollenhauer (1984) Monensininduced swelling of Golgi apparatus cisternae mediated by a proton gradient. Eur. J. Cell. Biol. 34: 1-8.

Bowman, C: L., and H. K. Kimelberg (1984) Excitatory amino acids directly depolarize rat brain astrocytes in primary culture. Nature 311: 656-659.

Bowman, C. L., H. K. Kimelberg, M. V. Frangakis, Y. Berwald-Netter, and C. Edwards (1984) Astrocytes in primary culture have chemically activated sodium channels. J. Neurosci. 4: 1527-1534.

Boyne, A. F., R. Dudek, R. Wierwille, and N. Brookes (1984) Quick freezing preserves endoplasmic reticular channels through cell membranes in astrocytes and beta cells. J. Cell. Biol. 99: 94a.

Brookes, N. (1984) Neurohumoral influences and $\left[{ }^{3} \mathrm{H}\right] 2$-deoxyglucose uptake in primary astrocytes. Fed. Proc. 43: 289

Brookes, N., and P. Yarowsky (1984) The effect of monensin on $\left[{ }^{3} \mathrm{H}\right] 2$ deoxyglucose uptake in cultured astrocytes. Abstr. IUPHAR Int. Congr. Pharmacol. 9: 592.

Brookes, N., and P. J. Yarowsky (1985) Determinants of deoxyglucose uptake in cultured astrocytes: The role of the sodium pump. J. Neurochem. 44: 473-479.

Cunningham, V. J., and J. E. Cremer (1981) A method for the simultaneous estimation of regional rates of glucose influx and phosphorylation in rat brain using radiolabeled 2-deoxyglucose. Brain Res. 221: 319-330.

Ehersolt, C., M. Perez, and J. Bockaert (1981) $\alpha_{1}$ and $\alpha$, Adrenergic receptors in mouse brain astrocytes from primary cultures. J. Neurosci. Res. $6: 643-652$.

Feinstein, M. B., E. G. Henderson, and R. I. Sha'afi (1977) The effects of alterations of transmembrane $\mathrm{Na}^{+}$and $\mathrm{K}^{+}$gradients by ionophores (nigericin, monensin) on serotonin transport in human blood platelets. Biochem. Biophys. Acta 468: 284-295.

Glickman, J., K. Croen, S. Kelly, and Q. Al-Awquati (1983) Golgi membranes contain an electrogenic pump in parallel to a chloride conductance. J. Cell Biol. 97: 1303-1308.

Harden, T. K., and K. D. McCarthy (1982) Identification of the beta adrenergic receptor subtype on astroglia purified from rat brain. $J$. Neurochem. 43: 600-605.

Hertz, L., A. Schousboe, N. Boechler, S. Mukerji, and S. Fedoroff (1978) Kinetic characteristics of the glutamate uptake into normal astrocytes in cultures. Neurochem. Res. 3: 1-14.

Hösli, L., E. Hösli, U. Schneider, and W. Wiget (1984) Evidence for the existence of histamine $\mathrm{H}_{1}$ - and $\mathrm{H}_{2}$-receptors on astrocytes of cultured rat central nervous system. Neurosci. Lett. 48: 287-291.

Kimelberg, H. K., S. Narvmi, and R. S. Bourke (1978) Enzymatic and morphological properties of primary rat brain astrocyte cultures and enzyme development in vivo. Brain Res. 153: 55-77.

Kimelberg, H. K., C. L. Bowman, S. Biddlecome, and R. S. Bourke (1979) Cation transport and membrane potential properties of primary astrocytes in cell culture from neonatal rat brains. Brain Res. 177: 533-550.

Kimelberg, H. K., C. L. Bowman, H. Hirata, C. Edwards, R. S. Bourke, and N. T. Slater (1983) Norepinephrine induced depolarization of astrocytes in primary culture. Soc. Neurosci. Abstr. 9: 449.

Lichtshtein, D., K. Dunlop, H. R. Kaback, and A. J. Blume (1979) Mechanism of monensin-induced hyperpolarization of neuroblastoma-glioma hybrid NG108-15. Proc. Natl. Acad. Sci. USA 76:25802584 .
Lund-Andersen, H., C. S. Kjeldsen, L. Hertz, and H. E. Brondsted (1976) Uptake of glucose analogues by rat brain cortex slices: $\mathrm{Na}^{+}$independent membrane transport. J. Neurochem. 27: 369-373.

Mata, M., D. J. Fink, H. Gainer, C. B. Smith, L. Davidsen, H. Savaki, W. J. Schwartz, and L. Sokoloff (1980) Activity-dependent energy metabolism in rat postcrior pituitary primarily reflects sodium pump activity. J. Neurochem. 34: 213-215.

Medzihradsky, F., O. Z. Sellinger, P. S. Nandhasri, and J. C. Santiago (1972) ATPase activity in glial cells and in neuronal perikarya of rat cerebral cortex during early postnatal development. J. Neurochem. 19: 543-545.

Moonen, G., and G. Franck (1977) Potassium effect on $\mathrm{Na}^{+}, \mathrm{K}^{+}$. ATPase activity of cultured newborn rat astroblasts during differentiation. Neurosci. Lett. 4: 263-267.

Morré, D. J., W. F. Boss, H. Grimes, and H. H. Mollenhauer (1983) Kinetics of Golgi apparatus membrane flux following monensin treatment of embryogenic carrot cells. Eur. J. Cell Biol. 30: 25-32.

Nordenberg, J., K. H. Stenzel, and A. Novogrodsky (1984) The $\mathrm{Na}^{+}$. ionophore monensin enhances glucose uptake in mouse thymocytes. Int. J. Biochem. 16: 837-840.

Phillips, T. E., and A. F. Boyne (1984) Liquid nitrogen-based quick freezing: Experiences with bounce-free delivery of cholinergic nerve terminals to a metal surface. J. Electron Micr. Technol. 1: 9-30.

Phillis, J. W. (1977) Physiological and pharmacological studies on central synaptic transmission. In Cell Tissue and Organ Culture in Neurobiology, S. Federoff and L. Hertz, eds., pp. 93-97, Academic, New York.

Pressman, B. C., and M. Fahim (1982) Pharmacology and toxicology of the monovalent carboxylic ionophores. Annu. Rev. Pharmacol. Toxicol. 22: 465-497.

Schousboe, A., H. Fosmark, and B. Formby (1976) Effect of serum withdrawal on $\mathrm{Na}^{+}, \mathrm{K}^{+}$-ATPase activity in astrocytes cultured from dissociated brain hemispheres. J. Neurochem. 28: 897-916.

Shapiro, D. L. (1973) Morphological and biochemical alterations in fetal rat brain cells cultured in the presence of monobutyryl cyclic AMP. Nature 241: 203-204.

Smith, J. B., and E. Rozengurt (1978) Serum stimulates the $\mathrm{Na}^{+}, \mathrm{K}^{+}$ pump in quiescent fibroblasts by increasing $\mathrm{Na}^{+}$entry. Proc. Natl. Acad. Sci. USA 75: 5560-5564.

Sokoloff, L. (1984) Metabolic Probes of Central Nervous System Activity in Experimental Animals and Man. Sinauer, Sunderland, MA.

Sokoloff, L., M. Reivich, C. Kennedy, M. H. Des Rosier, C. S. Patlak, K. D. Pettigrew, O. Sakurada, and M. Shinohara (1977) The $\left[{ }^{14} \mathrm{C}\right]$ deoxyglucose method for the measurement of local cerebral glucose utilization: Theory, procedure and normal values in the conscious and anesthetized albino rat. J. Neurochem. 28: 897-916.

Somjen, G. G. (1975) Electrophysiology of neuroglia. Annu. Rev. Physiol. 37: 163-190.

Tang, C. M., M. W. Cohen, and R. K. Orkand (1980) Electrogenic pumps in axons and neuroglia and extracellular potassium homeostasis. Brain Res. 194: 283-286.

Tartakoff, A. M. (1983) Perturbation of the structure and function of the Golgi complex by monovalent carboxylic ionophores. In Methods in Enzymology, Vol. 98, E. Fleischer and B. Fleischer, eds., pp. 4759. Academic, New York.

Tartakoff, A. M., and P. Vassalli (1978) Comparative studies of intracellular transport of secretory proteins. J. Cell Biol. 79: 694-707.

Walz, W., and L. Hertz (1983) Electrophysiology of astrocytes in primary cultures. Soc. Neurosci. Abstr. 9: 447.

Walz, W., and L. Hertz (1984) Sodium transport in astrocytes. J. Neurosci. Res. 11: 231-239.

Weibel, E. R. (1973) Stereologic techniques for electron microscopic morphometry. In Principles and Techniques of Electron Microscopy, Vol. 3, M. A. Hayat, ed., pp. 237-296, Van Nostrand-Reinhold, New York.

Yarowsky, P. J., and N. Brookes (1982) Activation of $\left.{ }^{3} \mathrm{H}\right] 2$-deoxyglucose uptake in glial cell cultures. Soc. Neurosci. Abstr. 8: 238.

Yarowsky, P. J., and N. Brookes (1984) Veratrum alkaloids stimulate $\left[{ }^{3} \mathrm{H}\right] 2$-deoxyglucose uptake in astrocytes in primary culture. Soc. Neurosci. Abstr. 10:947.

Yarowsky, P. J., A. F. Boyne, and R. J. Johnson (1985) Cellular and subcellular localization of deoxyglucose uptake in antidromically stimulated superior cervical ganglion. Soc. Neurosci. Abstr. 11: 1124. 